Refining nursing assessment and management with a new post-anaesthetic care discharge tool to
minimise surgical patient risk

Street, M

http://hdl.handle.net/10026.1/12156

10.1111/jan.13779

Journal of Advanced Nursing

Wiley

All content in PEARL is protected by copyright law. Author manuscripts are made available in accordance with publisher policies. Please cite only the published version using the details provided on the item record or document. In the absence of an open licence (e.g. Creative Commons), permissions for further reuse of content should be sought from the publisher or author. 


\title{
Refining nursing assessment and management with a new postanaesthetic care discharge tool to minimize surgical patient risk
}

\author{
Maryann Street $^{1,2,3}$ (D) $\mid$ Nicole M. Phillips ${ }^{1,2}$ (D) $\mid$ Emily Haesler $^{4,5} \mid$ Bridie Kent $^{6}$
}

\footnotetext{
${ }^{1}$ School of Nursing and Midwifery, Deakin University, Geelong, Victoria, Australia

${ }^{2}$ Deakin University Centre for Quality and Patient Safety Research (QPS), Burwood, Victoria, Australia

${ }^{3}$ Deakin University QPS Eastern Health Partnership, Burwood, Victoria, Australia

${ }^{4}$ School of Nursing, Midwifery and Paramedicine, Curtin University, Bentley, Western Australia, Australia

${ }^{5}$ School of Nursing and Midwifery, Latrobe University, Melbourne, Victoria, Australia

${ }^{6}$ Faculty of Health and Human Sciences, University of Plymouth, Plymouth, UK
}

\section{Correspondence}

Maryann Street, Deakin University School of Nursing and Midwifery, c/- 221 Burwood Hwy, Burwood, Victoria 3125, Australia.

Email: maryann.street@deakin.edu.au

Funding information

The authors acknowledge Health

Contributions Fund (HCF) Research

Foundation for funding this study

\begin{abstract}
Aims: To evaluate use of an evidence-based discharge tool, the Post-Anaesthetic Care Tool and its impact on nursing assessment, communication, and management of patients in the postanaesthetic care unit.

Background: Postanaesthetic care unit nurses manage patients immediately after surgery and make clinical decisions on discharge readiness. There is a lack of evidence-based guidance on assessing, documenting, and communicating the patient's postoperative experience. The Post-Anaesthetic Care Tool, which includes instructions for assessing discharge readiness and incorporates the ISOBAR acronym, was developed following a comprehensive systematic review and expert consultation.

Design and Methods: This quasiexperimental, multicentre, nonrandomized study was conducted in three postanaesthetic care units in Australia. Participants were nurses providing care to adults postgeneral anaesthesia. Episodes of care were observed before $(N=723)$ and after $(N=694)$ introduction of the evidence-based tool. Statistical methods (Chi-Square and Mann-Whitney U-Tests) were undertaken to analyse nursing assessment, communication, and management outcomes before and after implementation of the Post-Anaesthetic Care Tool.

Results: The Post-Anaesthetic Care Tool was associated with statistically significant improvements in the frequency of nursing assessment and responsiveness to complications including pain, nausea/vomiting and hypothermia. After the tool's introduction, nurses requested more medical reviews. This was associated with increased recognition of clinical deterioration and significant improvements in clarity of handover from the postanaesthetic care unit to the ward.

Conclusions: The structured discharge tool, Post-Anaesthetic Care Tool, was associated with improved nursing management of patients in the postanaesthetic care unit and enabled early identification and response to clinical concerns.

KEYWORDS

adverse effects, clinical handover, nursing assessment, patient discharge, patient safety, postanaesthetic care unit, surgery
\end{abstract}




\section{1 | INTRODUCTION}

Nurses in the postanaesthetic care unit (PACU) have responsibility for assessment, ongoing monitoring and management of patients and for making clinical decisions on readiness for discharge from the unit. The nurse's role further extends to recording and communicating the patient's postoperative journey through nursing documentation and the clinical handover. Despite being an internationally consistent role of the PACU nurse, this study was prompted by the lack of evidence-based guidance available to assist the nurse in evaluating and documenting discharge readiness. Underpinned by an evidencebased review of the literature (Phillips, Street, Kent, Haesler, \& Cadeddu, 2013), the researchers developed the Post-Anaesthetic Care Tool (PACT) and sought to observe and analyse its impact on the ways nurses in one Australian health network undertook patient assessment for discharge, management of adverse events and communication of the patient's condition and management plan.

\section{1 | Background}

In the period immediately following general anaesthetic there is a need for vigilant monitoring of postsurgical patients due to the risk for clinical deterioration. Discharge from the PACU before the patient is adequately stabilized may increase the risk of postsurgical adverse events, including respiratory and cardiac events, uncontrolled pain, nausea and vomiting, and haemorrhage (Young \& Purdy, 2006). In the postoperative period, the PACU nurse has a key responsibility for monitoring patient progress, managing adverse effects of anaesthetic, determining when medical assessment and/or intervention is required, assessing and managing postoperative pain and ensuring an adequate plan for management on the general ward is in place prior to PACU discharge (Smedley, 2010).

Although criteria for PACU discharge are recommended by anaesthetists internationally (American Society of Anesthesiologists Task Force on Postanesthetic Care 2013; Anaesthetists of Great Britain and Ireland 2013, Australian and New Zealand College of Anaesthetists 2006, Laszlo, Fernando, \& Zeev, 2009), clinical decision-making about patients' readiness for discharge is generally undertaken by the PACU nurse. There are a wide range of PACU discharge checklists to assist nurses in evaluating readiness for discharge from the PACU, including the widely used Aldrete score (Aldrete, 1995, 1998). These tools assign a score for each observed vital sign (blood pressure, oxygen saturation, conscious state, etc.) and a patient must achieve a minimum score to be assessed as clinically stable for discharge from the PACU. Two systematic reviews have identified the lack of strong clinical evidence underpinning most PACU discharge checklists (Phillips et al., 2013; American Society of Anesthesiologists Task Force on Postanesthetic Care 2013). Despite the paucity of evidence on the value of monitoring any specific patient variable, there is consensus in the field that use of standardized discharge assessment criteria is associated with fewer adverse events and improved postanaesthesia care outcomes for patients (Laszlo et al., 2009; Phillips, Street, Kent, \& Cadeddu, 2014).

\section{Why is this research needed?}

- There was a lack of evidence-based guidance available for nurses in the Post-Anaesthetic Care Unit on assessment and management for discharge readiness, or communication of the patient's postoperative experience immediately after surgery and anaesthesia.

\section{What are the key findings?}

- This study describes the development and evaluation of the Post-Anaesthetic Care Tool that is a structured tool incorporating evidence-based nursing assessment, communication and management for safe patient discharge from the postanaesthetic care unit.

- The findings highlight that using the Post-Anaesthetic Care Tool promoted nursing assessment and management of patients in the immediate postoperative period, enhanced nurses' recognition and response to clinical deterioration, by seeking medical review and ensuring the patient was ready for discharge from the postanaesthetic care unit

- This study also demonstrated that using the Post-Anaesthetic Care Tool improved the exchange of information between nurses during clinical handover from postanaesthetic care unit to the ward.

\section{How should the findings be used to influence policy/practice/research/education?}

- Using the Post-Anaesthetic Care Tool can assist in assessing readiness for discharge and delivering a comprehensive clinical handover from the postanaesthetic care unit, which are both important components for patient safety.

After assessing the patient as ready to be discharged from the PACU, the nurse's final responsibility is to promote continuity of patient management by providing the ward nurse with a comprehensive handover. Failure to pass on significant information regarding the patient's experience and ongoing care needs is an identified contributor to adverse events (Botti et al., 2009; Randmaa, Swenne, Martensson, Hogberg, \& Engstrom, 2016; Rose \& Newman, 2016; Watson, Manias, Geddes, Della, \& Jones, 2015).

The World Health Organisation (2007) has identified clinical handover as being an important exchange of information directly associated with patient safety. Minimal guidelines on the handover procedure and consensus recommendations suggest that handover to ward staff should include an indication of relevant medications administered in the operating theatre and PACU and full clinical details with emphasis on ongoing concerns and infusions requiring management (Australian College of Operating Room Nurses 2016). 
Formal handover checklists may improve clinical handover (Whitaker et al., 2013). ISOBAR (Porteous, Stewart-Wynne, Connolly, \& Crommelin, 2009; Yee, Wong, \& Turner, 2009) is one of several standardized communication tools to improve the exchange of information in clinical handovers. ISOBAR and similar structured tools for verbal communication have consistently been associated with significant improvements in nursing processes and reduction in omission of vital information during handover in a wide range of clinical settings and countries (Gardiner, Marshall, \& Gillespie, 2015; Kerr, Klim, Kelly, \& McCann, 2016; Petrovic, Martinez, \& Aboumatar, 2012).

International research on structured communication practices in the perioperative setting has focused on handover between anaesthetists, or handover from the anaesthetist to PACU staff (Boat \& Spaeth, 2013; Botti et al., 2009; Bourdon, 2015; Coleman, Redley, Wood, Bucknall, \& Botti, 2015; Dutton, 2014; Grover \& Duggan, 2013; Kitney et al., 2016; Lane-Fall, 2016; Manser, Foster, Flin, \& Patey, 2013; Milby, Bohmer, Gerbershagen, Joppich, \& Wappler, 2014; Randmaa, Martensson, Swenne, \& Engstrom, 2015; Robins \& Dai, 2015; Salzwedel et al., 2013; Smith, Pope, Goodwin, \& Mort, 2008). The existing literature related to doctor to nurse handover suggests that introduction of standardized assessment, documentation and communication procedures can improve patient safety and quality of care, particularly in clinical areas of high stress (Botti et al., 2009; Kitney et al., 2016; Randmaa et al., 2016) and constant patient turnover as seen in the PACU. However, handover on discharge from the PACU has received limited attention in the literature and to our knowledge no formal evaluation of a structured handover tool has previously been conducted in this setting.

The need for a standardized discharge tool for assessing readiness for PACU discharge was identified. This study sought to evaluate a recently developed assessment and handover tool, the PACT, in multiple sites in one large healthcare network in Melbourne, Australia.

\section{2 | THE STUDY}

\subsection{Aim}

This study aimed to evaluate use of an evidence-based discharge tool for nursing assessment and management of patients in the PACU and communication of the patient's postoperative experience. This paper focuses on the hypothesis that use of the PACT will enhance nurses' recognition and response to patients at risk of deterioration in the PACU, thus improving patient outcomes. The findings relating to detailed patient outcomes have been published separately (Street, Phillips, Mohebbi, \& Kent, 2017).

\section{2 | Study design}

This study used a prospective quasi-experimental design. The methods were developed and published a-priori (Street, Phillips, Kent, Colgan, \& Mohebbi, 2015). The study was conducted at three PACUs in hospitals in a large healthcare network, in metropolitan Melbourne, Victoria. Prior to the introduction of the PACT intervention there was no standardized network-wide PACU discharge tool in place and the hospital network management and PACU clinical teams all expressed a need to introduce an evidencebased tool. The three PACUs that were involved in the study differed in the type and complexity of surgery performed and the acuity of patients. The first site (PACU 1) was situated in a 180-bed hospital, the second site (PACU 2) was situated in a 400 bed hospital with an intensive care unit (ICU) and PACU 3 was in a 280 bed outer metropolitan hospital with ICU. In all PACUs, the patients were discharged either to a ward or day procedure unit. At PACU 1 and PACU 2 nursing handover was conducted in the PACU where the ward nurse received the patient, whereas in PACU 3 the PACU nurse accompanied the patient to the receiving ward and the handover was conducted in the ward.

\section{3 | Participants}

The unit of analysis was episodes of patient care provided to adults undergoing planned elective surgery during the study periods. Exclusion criteria were patients who had undergone an emergency procedure, those who did not have a general anaesthetic for their procedure or had a planned ICU admission directly from the operating room or PACU.

\section{4 | Intervention}

The intervention of interest in this study was the PACT. The tool was developed in response to the lack of a standardized evidencebased discharge tool to record patient readiness for discharge from PACUs in the local health network where this study was conducted. Before implementation of the PACT, PACU nurses used different documentation for nursing assessment, communication and management of patients in each site. PACU 1 had a single box to indicate the patient was assessed as ready for discharge from the PACU. At the second site (PACU 2) a modified Aldrete scoring system was used, whereas at PACU 3 a list of criteria, which were not validated, were used to assess patient readiness for discharge.

The development of the PACT was underpinned by a systematic review of post anaesthetic discharge assessment criteria (Phillips et al., 2013) and an international consensus study including anaesthetists and perioperative nurses (Phillips et al., 2014), both of which identified essential criteria for the nursing assessment of patient readiness for discharge from the PACU. Based on the findings of these two studies, the research team incorporated new assessment criteria into the local health network's Post Anaesthetic Care Record. This resulted in the documentation having additional criteria for patient assessment on discharge.

A subcommittee of nursing and medical clinicians, researchers, and representatives of the local health network oversaw the development of the PACT. The subcommittee reviewed the research underpinning the PACT's development and contributed to its refinement to conform with the policies and procedures of the health network, particularly with respect to local guidelines relating to the 
recognition and response to patient clinical deterioration. The PACT was implemented in all three PACUs on the same day, 17 March 2014.

The range across which the clinical observations may activate a Medical Emergency Team (MET) review were standardized on the PACT and based on the current guidelines and underpinning research (Australian Commission on Safety and Quality in Healthcare 2012; Phillips et al., 2013; Phillips et al., 2014). Colour shading consistent with MET call criteria was included in the PACT. PACU nurses were able to request a medical review and modification of the discharge criteria on a case-by-case basis by an anaesthetist or surgeon. Modifications, individualized to the patient included altered criteria for respiratory rate, oxygen saturation, systolic blood pressure, heart rate, temperature, or conscious state. The new PACT included clear instructions for nurses assessing a patient's readiness for discharge from the PACU (Box 1).

In addition to providing a record of the patient's clinical progress in PACU and discharge criteria, the PACT was designed to incorporate a standardized clinical handover tool, ISOBAR (Porteous et al., 2009; Yee et al., 2009). The ISOBAR acronym (Box 2) was presented vertically on the PACT and included brief explanatory notes to prompt and assist PACU nurses regarding components of a handover report.

The PACT was circulated to clinical staff prior to formal introduction of the tool to ensure familiarization with the tool's content. Education and support was provided to nursing staff on the introduction of the PACT to the hospitals. Posters with information on how to complete the PACT were displayed at each site. Perioperative nursing educators conducted sessions which enabled feedback by the nurses using the tool to address any issues and were accessible for assistance and training. Use of the PACT was an iterative process, with specific local issues in implementation being addressed as required.

In the three PACUs, nurse-to-patient ratio in both phases was maintained in compliance with Australian College of Perioperative Nurses (ACORN) standards (Australian College of Operating Room Nurses 2016). Nurse-to-patient ratio varies depending on patient acuity and period in PACU (on arrival, stabilization, ready for discharge) from an initial two nurses to one patient to a possible one nurse to three patients. There was no major staff attrition or other structural changes to the operation of the PACUs between the two data collection phases.

\subsection{Data collection}

Data were collected in the three PACUs from June - October in 2012 prior to introduction of the PACT (Phase 1) and then between July and September 2014, after implementation of the PACT (Phase 2). The interval of 2 years between pre- and post-data collection was due to the time required to develop the PACT and standardize nursing practice in three PACU sites.

Data related to nursing assessment and management, including handover to the ward nurse, were collected by research nurses through observation of nursing care in the PACU. Observation data were recorded using "TapForms" (৫2013 Tap Zapp Software Inc.) iPad

\section{BOX 1 Discharge Criteria in PACT}

Patients were required to meet the following discharge criteria:

- Last 2 sets of observations are not within a range that requires activation of the Medical Emergency Team (MET)

- Ongoing pain management has been ordered

- No active vomiting.

- Dermatome level is at least T4 (if applicable), and

- All surgical concerns have been addressed e.g. active bleeding.

\section{BOX 2 ISOBAR acronym for clinical nursing handover}

(Porteous et al., 2009)

Introduction/identify (yourself and patient).

Situation (what has happened?).

Observation (recent vital signs, primary and secondary assessment).

Background (tell the story).

Assessment (what do you think is going on?).

Request (what do you want from the handover nurse?).

application. Data, including patient demographics, physiological parameters, and documentation of clinical nursing care were collected by research nurses from patient records after hospital discharge. Patient demographic characteristics collected from medical records included age, gender, measures of patient acuity prior to surgery (American Society of Anaesthesiologists [ASA] score, Charleson Comorbidity Score), surgical procedure, day of admission, and discharge destination.

Outcome measures related to nurse behaviours included nursing assessment and management of adverse events, time for completion, and sections completed of the PACT documentation, assessment of the patient readiness for discharge and the duration and content of nursing handover on discharge from PACU. Patient-related outcome measures included nurses' recognition of complications and adverse events, the length of stay in PACU and hospital. In addition, in each study phase the time taken by nurses to complete documentation was observed for a random subsample of 25 patient episodes of care.

\section{6 | Statistical analysis}

Descriptive statistics (frequencies, means, standard deviations, medians, and interquartile ranges) were used to describe the sample and compare Phase 1 and Phase 2. Nursing assessment and management outcomes for each episode of patient care were analysed as categorical variables using Pearson's chi-square test, with specific nursing behaviours defined as having been performed or not performed. Between-group differences in patient outcomes were compared using 
the Mann-Whitney U-test for continuous variables and Pearson's chisquare test for categorical variables. Time spent by nurses completing documentation was calculated from the observed time spent on documentation per episode of patient care. Data were analysed using SPSS version 22 (IBM SPSS Statistics, Inc. Chicago, IL).

\section{7 | Ethical consideration}

Ethics clearance was obtained from the Human Research and Ethics Committee of the health network and from the Deakin University Human Research Ethics Committee. As the study was assessed as low risk due to its audit nature and the lack of collection of patientrelated data other than that required for regular patient care, a waiver of consent for patients was granted. The nurses were informed of the study via a participant information form and gave verbal consent to be observed. The nurses being observed could choose to opt out at any stage and when this did occur, the research nurse stopped further observation and the episode of patient care was deleted from the study.

\subsection{Validity and reliability}

Data collected by direct observation in the PACU was carried out by research nurses familiar with this clinical area and with experience in critical care nursing, therefore increasing the reliability of the study. Interrater reliability was assessed at the outset and additional training was provided to ensure consistency of data collection between research nurses. Although individual research nurses were not blinded to the aims of the study, as the data collection phases were conducted 2 years apart this would have reduced the likelihood of observer bias due to the extended time frame.

Expert nurses and academics familiar with the role of PACU nurses determined the content validity of the data collection tool used for observation of nursing assessment and management of patients in the PACU. Some of the data collection was through patient record audits. This presents a potential risk to internal validity due to incomplete documentation, or documentation that does not reflect the clinical experience. The researchers conducted crossvalidation using researcher observation of some variables explored in this study, particularly the conduct of targeted nursing interventions and time spent completing documentation.

\section{3 | RESULTS}

Across the three PACU sites, 723 episodes of patient care were included in Phase 1 and 694 in Phase 2. Mean age of patients was 51.5 years, $40.2 \%$ were male, mean ASA score was 1.9 and the mean Charleson Comorbidity score was 0.7. There were no significant differences between Phase 1 and Phase 2 patient cohorts with respect to age, gender, measures of acuity prior to undergoing surgery or admitting hospital (Table 1). However, patients from PACU 1 were younger, had lower ASA scores and lower comorbidity scores
TABLE 1 Patient admission characteristics by PACU site

\begin{tabular}{|c|c|c|c|}
\hline & $\begin{array}{l}\text { Phase } 1 \\
(N=723) \\
\text { mean }(S D)\end{array}$ & $\begin{array}{l}\text { Phase } 2 \\
(N=694) \\
\text { mean }(S D)\end{array}$ & $p$ value ${ }^{a}$ \\
\hline Age & $52.2(18.6)$ & $50.9(17.4)$ & 0.171 \\
\hline PACU 1 & $44.1(15.0)$ & $43.6(14.7)$ & \\
\hline PACU 2 & $56.6(18.2)$ & $53.7(17.6)$ & \\
\hline PACU 3 & $55.7(20.0)$ & $56.6(17.2)$ & \\
\hline ASA score & $1.9(0.78)$ & $1.9(0.74)$ & 0.290 \\
\hline PACU 1 & $1.65(0.68)$ & $1.64(0.62)$ & \\
\hline PACU 2 & $2.1(0.85)$ & $2.1(0.80)$ & \\
\hline PACU 3 & $2.0(0.71)$ & $1.9(0.70)$ & \\
\hline Comorbidity score & $0.69(1.35)$ & $0.66(1.24)$ & 0.736 \\
\hline PACU 1 & $0.21(0.77)$ & $0.43(0.87)$ & \\
\hline PACU 2 & $1.05(1.58)$ & $0.96(1.60)$ & \\
\hline \multirow[t]{2}{*}{ PACU 3} & $0.74(1.36)$ & $0.50(0.76)$ & \\
\hline & $n(\%)$ & $n(\%)$ & $p$ value ${ }^{\mathrm{b}}$ \\
\hline Gender, male & 301 (41.6) & $269(38.8)$ & 0.271 \\
\hline PACU 1 & $78(32.0)$ & $62(25.4)$ & \\
\hline PACU 2 & $139(47.3)$ & $125(43.6)$ & \\
\hline PACU 3 & $84(45.4)$ & $82(50.3)$ & \\
\hline Admitting hospital & & & 0.648 \\
\hline PACU 1 & $243(33.7)$ & $244(35.2)$ & \\
\hline PACU 2 & $295(40.7)$ & 287 (41.3) & \\
\hline PACU 3 & $185(25.6)$ & $163(23.5)$ & \\
\hline
\end{tabular}

${ }^{\mathrm{a}}$ Independent samples $t$-test.

bearson's $\chi^{2}$.

than those cared for in PACU 2 or PACU 3 (Table 1). There was no difference in the discharge destination from PACU, with $45.9 \%$ of patients discharged to the day procedure unit and $42.3 \%$ discharged to the ward in both phases $(p=0.137)$.

\subsection{Nursing assessment of patient readiness for discharge and management of adverse events}

Introduction of the PACT was associated with significant changes in nursing assessment of and responsiveness to, postoperative complications (Table 2). Significant increases $(p<0.001)$ were observed in Phase 2, for nursing assessment and response to pain, including documenting a pain score, increasing analgesia administration, documented ongoing analgesia regimen for the post-PACU period and providing a warming blanket. Assessment of temperature increased in the second phase of the study $(91.6 \%$ vs. $95.5 \%, p=0.004)$. In Phase 2, significantly more patients had an assessment of nausea and vomiting documented in the PACU notes $(p<0.001)$ and more antiemetics were administered in response to that assessment (49.2\% vs. $84.8 \%, p=0.002$ ). The above findings were consistent between the three PACUs.

Nurses recognized clinical deterioration requiring a medical consultation more often in the second phase of the study. There was a significant increase between Phase 1 and Phase 2 in nursing requests for medical 
TABLE 2 Nursing assessment of readiness for discharge from the PACU and management of postoperative complications

\begin{tabular}{|c|c|c|c|}
\hline & $\begin{array}{l}\text { Phase } 1 \\
(N=723) \\
\%\end{array}$ & $\begin{array}{l}\text { Phase } 2 \\
(N=694) \\
\%\end{array}$ & $p$ value $^{a}$ \\
\hline \multicolumn{4}{|l|}{ Pain } \\
\hline Analgesia administered & 37.2 & 54.2 & $<0.001$ \\
\hline Pain score recorded on discharge & 76.0 & 83.0 & $<0.001$ \\
\hline \multicolumn{4}{|l|}{ Nausea and vomiting } \\
\hline Assessed and recorded & 59.7 & 92.4 & $<0.001$ \\
\hline Antiemetic administered & 49.2 & 84.8 & 0.002 \\
\hline Use of warming blankets & 26.5 & 61.5 & $<0.001$ \\
\hline \multicolumn{4}{|l|}{ Hypothermia } \\
\hline Recording temperature & 91.6 & 95.5 & 0.004 \\
\hline \multicolumn{4}{|l|}{ Medical review } \\
\hline Medical consultation requested & 18.9 & 30.4 & $<0.01$ \\
\hline All discharge criteria met & 73.6 & 66.5 & 0.004 \\
\hline
\end{tabular}

aPearson's $\chi^{2}$.

review of patients in the PACU $(18.9 \%$ vs. $30.4 \%, p<0.001)$ and this finding was consistent across PACU sites (Table 2). Requests for medical review were most often in response to patients being assessed with bradycardia ( $4 \%$ vs. $12 \%$ ), pain ( $6 \%$ vs. $8 \%$ ) and postoperative nausea and vomiting $(0.6 \%$ vs. $2.0 \%)$. The increase in medical review requests was accompanied by an increase in alteration of medical emergency team (MET) call criteria $(6.5 \%$ vs. $12.8 \%, p<0.001)$ and a reduced number of patients who were discharged from PACU with all discharge criteria met $(73.6 \%$ vs. $66.5 \%, p=0.004$; Table 2$)$.

\subsection{Patient outcomes}

In total, $24 \%$ of patients experienced an adverse event and commonly these occurred before the patient was discharged from the PACU. Nurses' recognition of adverse events in PACU increased significantly from Phase 1 to Phase 2 ( $8.3 \%$ vs. $16.7 \%$; $p<0.001$ ); reflected in significant increases for PACU sites 1 and 2 and a small nonsignificant increase for PACU 3 (Table 3). There was no overall change in adverse events following PACU discharge (16.5\% vs. $16.9 \%$ ), however, again site variation was noted (Table 3 ).

Increased adverse events in PACU were accompanied by a significant eight-minute increase in the median PACU stay (Phase 1, 45 min [IQR 33-65] vs. Phase 2, 53 min [IQR 41-70]; $p<0.001$ ). Median hospital stay was also significantly longer in Phase 2 $(p<0.001)$. In both Phases patients who had an adverse event in PACU had longer stay in PACU and hospital than those who did not have an adverse event. However, length of stay in both PACU and hospital was shorter in Phase 2 for patients who had experienced an adverse event in PACU (Table 3).

\section{3 | Completion of nursing documentation}

Nurses spent approximately $23 \%$ of the duration of the patients' stay in PACU recording information in the patient record. Introduction of the PACT was not associated with a significant change in the median time spent completing documentation (Phase 1, $14.6 \mathrm{~min}$ [IQR 10.9-17.1] vs. Phase 2, $13.9 \mathrm{~min}$ [IQR 11.9-16.3]; $p=0.857)$.

TABLE 3 Length of stay in PACU and hospital comparing all patients to those who experienced an adverse event in PACU, and site variation for nursing recognition of adverse events

\begin{tabular}{|c|c|c|c|}
\hline & $\begin{array}{l}\text { Phase } 1(\mathrm{~N}=724) \\
\text { Mdn [IQR] }\end{array}$ & $\begin{array}{l}\text { Phase } 2(N=694) \\
\text { Mdn [IQR] }\end{array}$ & $p$ value $^{\mathrm{a}}$ \\
\hline \multicolumn{4}{|l|}{ Length of stay in PACU (minutes) } \\
\hline All patients & 45 [33-65] & $53[41-70]$ & $<0.001$ \\
\hline Patients with PACU adverse event & $100[74-143]$ & 84 [61-117] & 0.027 \\
\hline \multicolumn{4}{|l|}{ Length of hospital stay (days) } \\
\hline All patients & $0.5[0.3-2.0]$ & $1.0[0.3-2.0]$ & 0.026 \\
\hline \multirow[t]{2}{*}{ Patients with PACU adverse event } & $2.0[1.0-4.0]$ & $1.0[0.5-2.0]$ & 0.047 \\
\hline & $\%$ & $\%$ & $p$ value $^{\mathrm{b}}$ \\
\hline \multicolumn{4}{|l|}{ Adverse events by site } \\
\hline In PACU (All patients) & 8.3 & 16.7 & $<0.001$ \\
\hline PACU 1 & 3.3 & 19.7 & $<0.001$ \\
\hline PACU 2 & 12.9 & 18.1 & 0.084 \\
\hline PACU 3 & 7.6 & 9.8 & 0.456 \\
\hline After PACU discharge (All patients) & 16.5 & 16.9 & 0.840 \\
\hline PACU 1 & 9.4 & 17.6 & 0.008 \\
\hline PACU 2 & 24.8 & 15.0 & 0.003 \\
\hline PACU 3 & 12.4 & 19.0 & 0.090 \\
\hline
\end{tabular}

Note. Mdn [IQR] Median [Interquartile range].

aMann-Whitney $U$ Test.

bPearson's $\chi^{2}$. 
There was a high level of completion of PACU documentation throughout the patient PACU stay in both phases of the study. Conscious state, oxygen saturation, respiratory rate, heart rate, and blood pressure were recorded in almost $100 \%$ of patient episodes of care. However, temperature was recorded for $91.6 \%$ of patients on arrival in PACU in Phase 1, significantly increasing in Phase 2 to 95.5\% $(p=0.004)$. Vascular observations and pain score on discharge were often omitted.

There was a significant decrease in notification that all discharge criteria had been met prior to PACU discharge from Phase 1 to Phase 2 (73.6\% vs. 66.5\%; $p=0.004)$. For patients who experienced an adverse event in PACU, there was no significant difference between study phases in documentation of having met the discharge criteria (60\% in Phase 1 versus 62.8\% in Phase 2, $p=0.106$ ).

\subsection{Clinical handover from PACU nurse to ward nurse}

The median duration of nursing clinical handovers was 3.0 min (IQR 2.0-4.0) in both Phase 1 and Phase 2 of the study. For patients experiencing an adverse event, the median duration of the handover was significantly shorter in the second phase (Phase 1, 5.0 min [IQR 3.0-7.0] vs. Phase 2, $4.0 \mathrm{~min}$ [IQR 2.0-5.0], $p<0.001$ ). As reported in Table 4, there was a significant increase in Phase 2 in the proportion of handovers that contained all six elements of ISOBAR $(53.0 \%$ vs. $71.8 \%, p<0.001)$. This included significant increases in reporting of situation $(p=0.036)$, observations ( $p=0.049)$, and background $(p<0.001)$. However, there was large variation in the findings for the individual PACU sites (Table 4).

\section{4 | DISCUSSION}

This prospective study was the first of its kind to explore the influence of using a standardized, evidence-based PACU discharge tool on nursing assessment, response to and communication of postoperative complications. Documented rates of many adverse events increased significantly after the introduction of the PACT. This is a positive outcome, indicating that the tool enabled nursing staff to better recognize and respond to deterioration before the patient condition became critical. This finding is consistent with an Australian study that demonstrated an early increase in Rapid Response Team calls following the introduction of new documentation (O'Connell et al., 2016). The authors suggested the new features of the documentation, such as colour shading in the display of vital signs, had contributed.

In a Canadian survey of the relationship between PACU workload and adverse events, the researchers found that adverse events such as excessive pain or nausea and vomiting $(p=0.041)$ contributed significantly to nursing workload (Cohen et al., 1999). In the same study, major complications had a significant and much higher impact on nursing workloads. In this study, excessive pain was associated with significant changes in nursing management, with
TABLE 4 Inclusion of ISOBAR elements at clinical handover from PACU to ward

\begin{tabular}{|c|c|c|c|}
\hline & $\begin{array}{l}\text { Phase } 1 \\
(N=724) \\
\%\end{array}$ & $\begin{array}{l}\text { Phase } 2 \\
(N=694) \\
\%\end{array}$ & $p$ value ${ }^{a}$ \\
\hline All ISOBAR elements & 53.0 & 71.8 & $<0.001$ \\
\hline PACU 1 & 41.4 & 74.2 & $<0.001$ \\
\hline PACU 2 & 63.6 & 60.3 & 0.409 \\
\hline PACU 3 & 51.4 & 88.3 & $<0.001$ \\
\hline Identify & 81.1 & 84.3 & 0.107 \\
\hline PACU 1 & 75.0 & 87.3 & 0.001 \\
\hline PACU 2 & 83.0 & 77.4 & 0.088 \\
\hline PACU 3 & 85.9 & 92.0 & 0.073 \\
\hline Situation & 94.5 & 91.6 & 0.036 \\
\hline PACU 1 & 91.8 & 92.2 & 0.867 \\
\hline PACU 2 & 94.2 & 90.6 & 0.099 \\
\hline PACU 3 & 98.4 & 92.6 & 0.009 \\
\hline Observations & 90.5 & 87.2 & 0.050 \\
\hline PACU 1 & 90.6 & 88.1 & 0.379 \\
\hline PACU 2 & 89.8 & 84.0 & 0.037 \\
\hline PACU 3 & 91.4 & 91.4 & 0.984 \\
\hline Background & 72.6 & 82.0 & $<0.001$ \\
\hline PACU 1 & 61.5 & 80.7 & $<0.001$ \\
\hline PACU 2 & 81.0 & 77.7 & 0.333 \\
\hline PACU 3 & 74.2 & 91.4 & $<0.001$ \\
\hline Assessment & 86.7 & 89.6 & 0.091 \\
\hline PACU 1 & 85.7 & 89.8 & 0.168 \\
\hline PACU 2 & 93.5 & 88.2 & 0.024 \\
\hline PACU 3 & 77.3 & 92.0 & $<0.001$ \\
\hline Recommendation or request & 89.6 & 90.1 & 0.788 \\
\hline PACU 1 & 80.7 & 92.6 & $<0.001$ \\
\hline PACU 2 & 92.9 & 87.1 & 0.021 \\
\hline PACU 3 & 96.2 & 91.4 & 0.060 \\
\hline
\end{tabular}

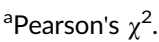

increases in conducting a pain assessment, administering analgesia and comfort measures (e.g., warming blankets) and ensuring an ongoing pain management plan was in place. Likewise, managing nausea and vomiting was associated with an increase in nursing response through assessment and administering antiemetics.

Observation of nursing time indicated that although the PACT triggered changes in nursing behaviour with respect to nursing assessment and management of adverse events, this was not associated with an increase in time spent on documentation and clinical handover. This is consistent with a previous study of bedside handover, which demonstrated significant improvements in nursing care tasks and documentation, with no change in the time of handover (Kerr, Lu, \& McKinlay, 2013). Although this study did not measure the impact of the PACT on nursing workload, the design and useability of the PACT may have contributed to the lack of change in documentation time when using the PACT. 
In this study, introduction of the PACT was associated with significant change in nursing behaviour in response to patient pain. After introduction of the PACT, documentation, assessment and management of postoperative pain increased significantly, with a corresponding increase in PACU nurses seeking medical review. Previous studies have shown that nursing documentation of postoperative pain is often inadequate (Abdalrahim, Majali, Stomberg, \& Bergbom, 2011; Bucknall, Manias, \& Botti, 2007; Idvall \& Ehrenberg, 2002; Manias, 2003). In one study (Karlsen, Kornmo, \& Dihle, 2015) that explored the effect of an education program on the behaviour of PACU nurses in relation to both documenting and assessing pain, the researchers noted that the design and complexity of the documentation in the Norwegian PACU was a significant barrier for nurses in documenting pain assessment and management. The authors assert that as a result, the education program had no significant impact on pain documentation (Karlsen et al., 2015).

In contrast, a randomized trial conducted in a French tertiary hospital reported significant increases in documentation of pain in the PACU after delivery of education sessions when introducing a simple visual analogue scale (Ravaud et al., 2004). The experiences and opinion of international researchers exploring pain documentation in PACU suggest the level of documentation complexity is an important consideration (Brown, 2008; Karlsen et al., 2015; Ravaud et al., 2004). The PACT includes documentation of pain score to complete alongside vital sign assessment. Its simplicity and inclusion on the primary observation chart are likely related to the increases noted in documentation of pain.

"Ongoing pain management ordered" is a specific criterion included in the discharge criteria checklist. This is visually highlighted on the PACT, providing a prominent reminder to PACU nurses regarding the importance of pain assessment and management. The inclusion of current pain level as a criterion for PACU discharge has been suggested (Brent, 2010; Dunwoody, Krenzischek, Pasero, Rathmell, \& Polomano, 2008). However, there is no strong evidence to suggest a specific pain score is associated with better or poorer outcomes (Phillips et al., 2013). The focus on the PACT for ongoing pain management planning reflects the importance of addressing the patient's longer term recovery needs.

Another significant finding of this study was more appropriate documentation of discharge criteria after the adoption of the PACT. In Phase 1, discharge criteria were not standardized, and a discharge criteria tick box was available and used in over $70 \%$ of the episodes of patient care. In the second phase of the study, nurses requested more medical reviews in response to their assessment of the patient, which often led to individualized adjustment of discharge criteria. Consequently, fewer patients were discharged with all the relevant "Discharge Criteria Met" boxes ticked.

A retrospective study conducted in Australia found that $92 \%$ of patients in PACU who met the criteria for MET call activation were not reviewed by the medical team, despite nurse acknowledgement and management of their critical status (Guinane, Bucknall, Currey, $\&$ Jones, 2013). The study highlighted clinical practice where nursing staff regularly independently initiate treatment of clinical deterioration without requesting medical review of patients meeting MET criteria, with a significantly increased length of stay in the PACU (Guinane et al., 2013). In this study, the PACT was associated with an increase in MET review requests, most often in relation to patient pain or blood pressure status. However, in contrast to previous studies, patients who experienced an adverse event in the PACU in Phase 2, had a significant decrease in their length of stay in both the PACU and hospital, compared with those who experienced an adverse event in Phase 1 of the study. As this study did not have a control group of patients, the potential for confounders contributing to these changes must be acknowledged. Appropriate management of clinical deterioration has obvious benefits for the patient and the increased individualization of discharge criteria by the MET appears to have led to both greater structure and nuance in the nursing documentation of episodes of care and a decrease in hospital bed days.

After the introduction of the PACT, which clearly prompted nurses to use the structured ISOBAR handover format, there was a large, significant increase in the proportion of handovers containing all the elements of ISOBAR with no change in the duration of handover. Although fewer handovers included a description of the Situation and Observations, significantly more handovers included the patient's background. It should be emphasized that handovers in the three PACUs included in our study had high levels of inclusion of individual elements of ISOBAR, with only one element below $85 \%$ at baseline. This finding is in contrast to another recent Australian study (Kitney et al., 2016) that found poorer compliance with Identification (79.8\%) Background (27.6 to 30.6\%), Assessment (53.5\% to $95.5 \%$ ), and Recommendation or request (51.1\% to $76.2 \%$ ); however, Kitney et al. were exploring handover from anaesthetists to nurses.

Analysis of the ISOBAR data at the site level showed varied performance between sites, with the two smaller PACUs generally showing more statistically significant improvements than the largest hospital PACU. We propose that this finding relates to greater changes in practice and perspective in the facilities that had fewer standardized documentation and handover procedures.

\section{1 | Study limitations}

The study was conducted in one local health network and therefore lacks generalizability to other clinical settings. However, the researchers attempted to address this limitation through the inclusion of three unique PACUs, each representative of real-world clinical settings, with a diversity in the types of patients and surgery at the three sites. The homogeneity of the majority of study data across the three PACU sites suggests the findings are relevant to different PACU settings. However, all three PACUs were a part of the same local health network and both clinicians and managers had expressed a specific desire to be engaged in the development of an evidence-based PACU discharge tool; therefore, unique cultural attitudes and routines may have contributed to the findings. In future studies it would be advantageous to further explore the impact of PACT on the time nurses spend managing adverse events. 


\section{CONCLUSION}

Early identification of postoperative complications, including pain, nausea and vomiting, and hypothermia allows PACU nurses to implement management strategies more promptly, increasing patient comfort and decreasing the risk of rapid clinical deterioration. In this study, nurses were prompted to assess and identify emerging clinical issues when using the PACT. leading to improved patient management and revision of discharge criteria on an individualized basis. Using the PACT can assist in assessing readiness for discharge and delivering a comprehensive clinical handover from the PACU, which are both important components for patient safety. The overall outcome from improved clinical care guided by the PACT was early recognition of adverse events and decreased hospital length of stay for those patients who experience an adverse event in PACU, both of which are clinically significant to both patients and the healthcare system.

\section{RELEVANCE TO CLINICAL PRACTICE}

The PACT is an evidence-based discharge tool for nursing assessment and management of patients in the immediate postoperative period and communication of the patient's postoperative experience. Using this tool promotes timely recognition and response to clinical deterioration, as well as nursing management of symptoms such as pain, postoperative nausea and vomiting and hypothermia. Furthermore, the inclusion of the ISOBAR acronym for standardized clinical handover led to more complete communication of the patient's postoperative experience. This is especially relevant for patients who have a serious adverse event in PACU as the reduced length of stay in the PACU suggests that use of the PACT enabled earlier recognition and appropriate management of adverse events in PACU.

\section{ACKNOWLEDGEMENTS}

The authors acknowledge the support of Eastern Health executives, nursing managers and staff working in the perioperative area on the development of the Post-Anaesthetic Care Tool. We gratefully acknowledge the following nurses who conducted data collection: Leanne Barbazza, Monica Beninca, Jessica Guinane, Renata Mistarz, Nicole Robertson, Louise Thomas, Melissa Ayres. Faculty of Health Biostatistician, Mohammadreza Mohebbi provided advice in respect of the data analysis and we acknowledge his contribution.

\section{AUTHOR CONTRIBUTIONS}

All authors have agreed on the final version and meet at least one of the following criteria (recommended by the ICMJE (http://www.icmje.org/ recommendations/)):

- substantial contributions to conception and design, acquisition of data, or analysis and interpretation of data;
- drafting the article or revising it critically for important intellectual content.

\section{CONFLICT OF INTEREST}

The authors have no conflicts of interest to declare.

\section{ORCID}

Maryann Street iD http://orcid.org/0000-0002-5615-141X

Nicole M. Phillips (iD http://orcid.org/0000-0002-6821-4983

\section{REFERENCES}

Abdalrahim, M. S., Majali, S. A., Stomberg, M. W., \& Bergbom, I. (2011). The effect of postoperative pain management program on improving nurses' knowledge and attitudes toward pain. Nurse Education in Practice, 11(4), 250-255. https://doi.org/10.1016/j.nepr.2010.11.016

Aldrete, J. (1995). The post-anesthesia recovery score revisited. Journal of Clinical Anesthesia, 7(1), 89-91. https://doi.org/10.1016/09528180(94)00001-K

Aldrete, J. (1998). Modifications to the postanesthesia score for use in ambulatory surgery. Journal of Perianesthesia Nursing, 13(3), 148-155. https://doi.org/10.1016/S1089-9472(98)80044-0

American Society of Anesthesiologists Task Force on Postanesthetic Care (2013). Practice guidelines for postanesthetic care. Anesthesiology, 118(2), 1-17.

Anaesthetists of Great Britain and Ireland (2013). Immediate Post-anaesthesia Recovery 2013. London: AAGBI.

Australian College of Operating Room Nurses. (2016). Standards for perioperative nursing in Australia. 14th Edition. Retrieved from https:// www.acorn.org.au/.

Australian Commission on Safety and Quality in Healthcare. (2012). Recognising and responding to clinical deterioration in acute health care. Retrieved from http://www.safetyandquality.gov.au/wp-conte nt/uploads/2012/04/Quick-start-guide-to-Standard-9.pdf.

Australian and New Zealand College of Anaesthetists. (2006). Recommendations for the post-anaesthesia recovery room 2006. Vol. 2010 ANZCA. Retrieved from http://www.anzca.edu.au/resources/profes sional-documents/professional-standards/ps4.html.

Boat, A. C., \& Spaeth, J. P. (2013). Handoff checklists improve the reliability of patient handoffs in the operating room and postanesthesia care unit. Paediatric Anaesthesia, 23(7), 647-654. https://doi.org/10. 1111/pan.12199

Botti, M., Bucknall, T., Cameron, P., Johnstone, M. J., Redley, B., Evans, S., \& Jeffcott, S. (2009). Examining communication and team performance during clinical handover in a complex environment: The private sector post-anaesthetic care unit. Medical Journal of Australia, 190(11 Suppl), S157-S160.

Bourdon, L. (2015). Standardizing the OR to PACU patient hand over. AORN Journal, 101(2), P10-P12.

Brent, R. (2010). Patient assessment in recovery. Journal of Perioperative Practice, 20(3), 103-107. https://doi.org/10.1177/175045891002000303

Brown, D. N. (2008). Pain assessment in the recovery room. Journal of Perioperative Practice, 18(11), 480-489. https://doi.org/10.1177/ 175045890801801103

Bucknall, T., Manias, E., \& Botti, M. (2007). Nurses' reassessment of postoperative pain after analgesic administration. The Clinical Journal of Pain, 23(1), 1-7. https://doi.org/10.1097/01.ajp.0000210936.50816.49

Cohen, M., O'Brien-Pallas, L., Copplestone, C., Wall, R., Porter, J., \& Rose, K. (1999). Nursing workload associated with adverse events in the 
postanesthesia care Uunit. Anesthesiology, 91, 1882-1890. https:// doi.org/10.1097/00000542-199912000-00043

Coleman, K., Redley, B., Wood, B., Bucknall, T., \& Botti, M. (2015). Interprofessional interactions influence nurses' adoption of handover improvement. ACORN: The Journal of Perioperative Nursing in Australia, 28(1), 10-14.

Dunwoody, C. J., Krenzischek, D. A., Pasero, C., Rathmell, J. P., \& Polomano, R. C. (2008). Assessment, physiological monitoring and consequences of inadequately treated acute pain. Journal of Perianesthesia Nursing, 23(1 Suppl), S15-S27. https://doi.org/10.1016/j.jopan.2007.11.007

Dutton, R. P. (2014). Seamless anesthesia care: The handover process. Anesthesiology, 121(4), 673-674. https://doi.org/10.1097/ALN. 0000000000000400

Gardiner, T. M., Marshall, A. P., \& Gillespie, B. M. (2015). Clinical handover of the critically ill postoperative patient: An integrative review. Australian Critical Care, 28(4), 226-234. https://doi.org/10.1016/ j.aucc.2015.02.001

Grover, A., \& Duggan, E. (2013). Chinese whispers in the post anaesthesia care unit (PACU). Irish Medical Journal, 106(8), 241-243.

Guinane, J. L., Bucknall, T. K., Currey, J., \& Jones, D. A. (2013). Missed medical emergency team activations: Tracking decisions and outcomes in practice. Critical Care and Resuscitation, 15(4), 266-272.

Idvall, E., \& Ehrenberg, A. (2002). Nursing documentation of postoperative pain management. Journal of Clinical Nursing, 11(6), 734-742. https://doi.org/10.1046/j.1365-2702.2002.00688.x

Karlsen, N., Kornmo, R. H., \& Dihle, A. (2015). Assessing an educational program to improve documentation and reduce pain in hospitalized patients. Open Journal of Nursing, 5, 361-369. https://doi.org/ 10.4236/ojn.2015.54039

Kerr, D., Klim, S., Kelly, A. M., \& McCann, T. I. (2016). Impact of a modified nursing handover model for improving nursing care and documentation in the emergency department: A pre-and postimplementation study. International Journal of Nursing Practice, 22(1), 89-97. https://doi.org/10.1111/ijn.12365

Kerr, D., Lu, S., \& McKinlay, L. (2013). Bedside handover enhances completion of nursing care and documentation. Journal of Nursing Care Quality, 28(3), 217-225. https://doi.org/10.1097/NCQ.0b013e31828aa6e0

Kitney, P., Tam, R., Bennett, P., Buttigieg, D., Bramley, D., \& Wang, W. (2016). Handover between anaesthetists and post-anaesthetic care unit nursing staff using ISBAR principles: A quality improvement study. ACORN: The Journal of Perioperative Nursing in Australia, 29(1), 30-35.

Lane-Fall, M. B. (2016). No matter the perspective, anesthesia handoffs are problematic. Anesthesia \& Analgesia, 122(1), 7-9. https://doi.org/ 10.1213/ANE.0000000000001055

Laszlo, V., Fernando, G., \& Zeev, G. (2009). Quality and safety guidelines of postanaesthesia care: Working Party on Post Anaesthesia Care (approved by the European Board and Section of Anaesthesiology, Union Européenne des Médecins Spécialistes). European Journal of Anaesthesiology, 26(9), 715-721.

Manias, E. (2003). Medication trends and documentation of pain management following surgery. Nursing \& Health Sciences, 5(1), 85-94. https://doi.org/10.1046/j.1442-2018.2003.00140.x

Manser, T., Foster, S., Flin, R., \& Patey, R. (2013). Team communication during patient handover from the operating room: More than facts and figures. Human Factors, 55(1), 138-156. https://doi.org/10.1177/ 0018720812451594

Milby, A., Bohmer, A., Gerbershagen, M. U., Joppich, R., \& Wappler, F. (2014). Quality of post-operative patient handover in the post-anaesthesia care unit: A prospective analysis. Acta Anaesthesiologica Scandinavica, 58(2), 192-197. https://doi.org/10.1111/aas.12249

O'Connell, A., Flabouris, A., Kim, S. W., Horwood, C., Hakendorf, P., \& Thompson, C. H. (2016). A newly designed observation and response chart's effect on adverse inpatient outcomes and rapid response team activity. Internal Medicine Journal, 46(8), 909-916. https://doi.org/ 10.1111/imj.13137
Petrovic, M. A., Martinez, E. A., \& Aboumatar, H. (2012). Implementing a perioperative handoff tool to improve postprocedural patient transfers. Joint Commission Journal on Quality \& Patient Safety, 38(3), 135-142. https://doi.org/10.1016/S1553-7250(12)38018-5

Phillips, N. M., Street, M., Kent, B., \& Cadeddu, M. (2014). Determining criteria to assess patient readiness for discharge from postanaesthetic care: An international Delphi study. Journal of Clinical Nursing, 23(23-24), 3345-3355. https://doi.org/doi:10.1111/jocn. 12576

Phillips, N. M., Street, M., Kent, B., Haesler, E., \& Cadeddu, M. (2013). Post-anaesthetic discharge scoring criteria: Key findings from a systematic review. International Journal of Evidence Based Healthcare, 11, 275-284. https://doi.org/doi:10.1111/1744-1609.12044

Porteous, J., Stewart-Wynne, E. G., Connolly, M., \& Crommelin, P. F. (2009). iSoBAR - a concept and handover checklist: The national clinical handover initiative. Medical Journal of Australia, 190(11), 152.

Randmaa, M., Martensson, G., Swenne, C. L., \& Engstrom, M. (2015). An observational study of postoperative handover in anesthetic clinics; The content of verbal information and factors influencing receiver memory. Journal of Perianesthesia Nursing, 30(2), 105-115. https:// doi.org/10.1016/j.jopan.2014.01.012

Randmaa, M., Swenne, C. L., Martensson, G., Hogberg, H., \& Engstrom, M. (2016). Implementing situation-background-assessment-recommendation in an anaesthetic clinic and subsequent information retention among receivers: A prospective interventional study of postoperative handovers. European Journal of Anaesthesiology, 33(3), 172-178. https://doi.org/10.1097/EJA.0000000000000335

Ravaud, P., Keita, H., Porcher, R., Durand-Stocco, C., Desmonts, J. M., \& Mantz, J. (2004). Randomized clinical trial to assess the effect of an educational programme designed to improve nurses' assessment and recording of postoperative pain. British Journal of Surgery, 91(6), 692-698. https://doi.org/10.1002/(ISSN)1365-2168

Robins, H. M., \& Dai, F. (2015). Handoffs in the postoperative anesthesia care unit: Use of a checklist for transfer of care. AANA Journal, 83(4), 264-268.

Rose, M., \& Newman, S. (2016). Factors influencing patient safety during postoperative handover. AANA Journal, 84(5), 329-338.

Salzwedel, C., Bartz, H. J., Kuhnelt, I., Appel, D., Haupt, O., Maisch, S., \& Schmidt, G. N. (2013). The effect of a checklist on the quality of post-anaesthesia patient handover: A randomized controlled trial. International Journal for Quality in Health Care, 25(2), 176-181. https://doi.org/10.1093/intqhc/mzt009

Smedley, P. (2010). Safe staffing in the post anaesthetic care unit: No magic formula. British Journal of Anaesthetic and Recovery Nursing, 11(1), 3-8. https://doi.org/10.1017/S1742645610000057

Smith, A. F., Pope, C., Goodwin, D., \& Mort, M. (2008). Interprofessional handover and patient safety in anaesthesia: Observational study of handovers in the recovery room. British Journal of Anaesthesia, 101, 332-337. https://doi.org/10.1093/bja/aen168

Street, M., Phillips, N. M., Kent, B., Colgan, S., \& Mohebbi, M. (2015). Minimising post-operative risk using a Post-Anaesthetic Care Tool (PACT): Protocol for a prospective observational study and costeffectiveness analysis. British Medical Journal Open, 5(6), e007200.

Street, M., Phillips, N. M., Mohebbi, M., \& Kent, B. (2017). Effect of a newly designed observation, response and discharge chart in the Post Anaesthetic Care Unit on patient outcomes: A quasi-experimental study in Australia. British Medical Journal Open, 7(12), e015149. https://doi.org/doi:10.1136/bmjopen-2016-015149

Watson, B. M., Manias, E., Geddes, F., Della, P., \& Jones, D. (2015). An analysis of clinical handover miscommunication using a language and social psychology approach. Journal of Language and Social Psychology, 34(6), 687-701. https://doi.org/10.1177/0261927X15586200

Whitaker, D. K., Booth, H., Clyburn, P., Harrop-Griffiths, W., Hosie, H., Kilvington, B., ... Verma, R. (2013). Immediate post-anaesthesia recovery 2013. Anaesthesia, 68, 288-297. 
World Health Organisation (2007). Communication during patient handovers, Aide Memoir. Patient Safety Solutions, 1(3), 1-4.

Yee, K. C., Wong, M. C., \& Turner, P. (2009). "HAND ME AN ISOBAR": A pilot study of an evidence-based approach to improving shift-toshift clinical handover. Medical Journal of Australia, 190, S121-S124.

Young, G., \& Purdy, R. (2006). Post anaesthetic and postoperative care. In M. Sheppard, \& M. Wright (Eds.), Principles and practice of high dependency nursing (pp. 219-220). London, UK: Elsevier Health Sciences.
How to cite this article: Street M, Phillips NM, Haesler E,

Kent $\mathrm{B}$. Refining nursing assessment and management with a new postanaesthetic care discharge tool to minimize surgical patient risk. J Adv Nurs. 2018;00:1-11.

https://doi.org/10.1111/jan.13779

The Journal of Advanced Nursing (JAN) is an international, peer-reviewed, scientific journal. JAN contributes to the advancement of evidencebased nursing, midwifery and health care by disseminating high quality research and scholarship of contemporary relevance and with potential to advance knowledge for practice, education, management or policy. JAN publishes research reviews, original research reports and methodological and theoretical papers.

For further information, please visit JAN on the Wiley Online Library website: www.wileyonlinelibrary.com/journal/jan

\section{Reasons to publish your work in JAN:}

- High-impact forum: the world's most cited nursing journal, with an Impact Factor of 1.998 - ranked 12/114 in the 2016 ISI Journal Citation Reports @ (Nursing (Social Science)).

- Most read nursing journal in the world: over 3 million articles downloaded online per year and accessible in over 10,000 libraries worldwide (including over 3,500 in developing countries with free or low cost access).

- Fast and easy online submission: online submission at http://mc.manuscriptcentral.com/jan.

- Positive publishing experience: rapid double-blind peer review with constructive feedback.

- Rapid online publication in five weeks: average time from final manuscript arriving in production to online publication.

- Online Open: the option to pay to make your article freely and openly accessible to non-subscribers upon publication on Wiley Online Library, as well as the option to deposit the article in your own or your funding agency's preferred archive (e.g. PubMed). 